Article

\title{
Spatio-Temporal Patterns of Coastal Aquaculture Derived from Sentinel-1 Time Series Data and the Full Landsat Archive
}

\author{
Dorothee Stiller *(D), Marco Ottinger $(\mathbb{D}$ and Patrick Leinenkugel(i) \\ German Aerospace Center (DLR), German Remote Sensing Data Center (DFD), D-82234 Wessling, Germany \\ * Correspondence: dorothee.stiller@dlr.de; Tel.: +49-8153-28-3405
}

Received: 24 May 2019; Accepted: 13 July 2019; Published: 18 July 2019

check for updates

\begin{abstract}
Asia is the major contributor to global aquaculture production in quantity, accounting for almost $90 \%$. These practices lead to extensive land-use and land-cover changes in coastal areas, and thus harm valuable and sensitive coastal ecosystems. Remote sensing and GIS technologies contribute to the mapping and monitoring of changes in aquaculture, providing essential information for coastal management applications. This study aims to investigate aquaculture expansion and spatio-temporal dynamics in two Chinese river deltas over three decades: the Yellow River Delta (YRD) and the Pearl River Delta (PRD). Long-term patterns of aquaculture change are extracted based on combining a reference layer on existing aquaculture ponds for 2015 derived from Sentinel-1 data with annual information on water bodies extracted from the long-term Landsat archive. Furthermore, the suitability of the proposed approach to be applied on a global scale is tested based on exploiting the Global Surface Water (GSW) dataset. We found enormous increases in aquaculture area for the investigated target deltas: an 18.6-fold increase for the YRD (1984-2016), and a 4.1-fold increase for the PRD (1990-2016). Furthermore, we detect hotspots of aquaculture expansion based on linear regression analyses for the deltas, indicating that hotspots are located in coastal regions for the YRD and along the Pearl River in the PRD. A comparison with high-resolution Google Earth data demonstrates that the proposed approach can detect spatio-temporal changes of aquaculture at an overall accuracy of $89 \%$. The presented approach has the potential to be applied to larger spatial scales covering a time period of more than three decades. This is crucial to define appropriate management strategies to reduce the environmental impacts of aquaculture expansion, which are expected to increase in the future.
\end{abstract}

Keywords: aquaculture; food security; Landsat; Sentinel-1; temporal analysis; river delta; coastal region; China; Asia

\section{Introduction}

One major land-use and land-cover change of the last decades in coastal areas can be attributed to the expansion of aquaculture. Aquaculture defines any sort of aquatic organisms farmed and harvested in aqua farms, which are almost exclusively destined for human food consumption [1]. The majority of aquaculture is farmed in inland aquaculture basins, accounting for $63 \%$ of global production [1]. Aquaculture is the sector of food production systems with the highest growth rates. Several studies pointed out that aquaculture has the potential to reduce poverty across the world [2-4]. Due to population growth, aquaculture as a controlled system of protein production is powerful in contributing to food security and covering future nutrition demands, which positively influences human well-being $[5,6]$.

Asia is the hotspot region of global aquaculture production, accounting for $89.4 \%$ in 2016, followed by North and South America with 4.2\%, Europe with 3.7\%, Africa with 2.5\%, and Oceania with 0.3\% [7]. 
Thirteen Asian nations are among the top 25 producers of farmed aquatic species. The increase in aquaculture production for China has been enormous between 1995-2014 [1]. Country-wise, China is by far the top producer; it contributed 61.6\% to the aquaculture production worldwide in 2014 [1].

The enormous quantities of aquaculture goods produced in Asian aquafarms require high amounts of natural resources, such as land, water, and aquatic species, as well as non-natural resources, such as feeds, antibiotics, and artificial fertilizers [1]. The negative effects of aquaculture production on the state of the environment-especially the animal producing sector-are evident. The aquaculture industry heavily pollutes the surrounding waters both freshwater bodies or streams and seawater. Wastewater created during aquaculture production is often discharged unfiltered [8], causing the accumulation of pharmaceuticals [9] and heavy metals [10], accelerating eutrophication [5], and enhancing harmful algal blooms [11-13]. To make room for aquaculture ponds in coastal areas, mangrove forests get logged, which contribute to coastal protection, are key nursery habitats, and were found to positively impact filtration, e.g., of heavy metals [14,15]. Heavy metals originating in the industry can already be detected in aquaculture products [16], and the amounts even exceed Chinese safety guidelines [10]. Besides the pollution and deforestation of mangroves, the water consumption of aquaculture production leads to the excessive extraction of groundwater, which increases salinity [17]. Through groundwater pumping in the YRD, subsidence rates are higher than local and global sea-level rise, which exposes the population of Asian mega-deltas to various risks such as storm surges, saline groundwater, intensified flooding, and shoreline retreat [18].

Thus, aquaculture production is detrimental to the environment, and it will further expand [19]. In this context, it is fundamental to assess the dimensions on aquaculture and provide solid data for management applications. The Food and Agriculture Organization (FAO) provides the only global database on fisheries and aquaculture, which is commonly used in science and policy [20]. However, the reliability of this database has been called into question, assuming that numbers are underestimating reality, and improved monitoring is demanded [19]. Therefore, remote sensing serves to provide additional and objective information of aquaculture development and its provoked land-use and land-cover changes.

Remote sensing technologies can serve as a useful tool to determine aquaculture extent, and its dynamics and results may operate as an additional and independent source of data. Additionally, spatio-temporal patterns of aquaculture become discernible, which is crucial for the management of its expansion and its resources, to guarantee the maintenance of its positive implications and lower its negative effects. Different approaches exist to observe and quantify aquaculture based on remote sensing and GIS techniques using Landsat imagery. To assess bi-temporal changes in shrimp aquaculture, supervised classification approaches have been applied [21], and change detection methods were undertaken to reveal the influence of aquaculture on coastal ecosystems [22-26]. However, the majority of these studies investigate small-scale regions, e.g., single bays or lagoons [21,25], a few villages [26], or parts along the coastline [22,24], and rather focus on the quantification of aquaculture area. However, bitemporal approaches provide only a snapshot between two time points. To identify robust trends of aquaculture, assessments based on long-term time series are needed. Landsat data provide the ideal basis to firstly carry out an assessment on large spatial to global scales, and secondly, to detect spatio-temporal patterns of aquaculture expansion on multi-temporal scales. However, the spatial resolution of Landsat imagery is not sufficient to accurately map aquaculture on a single pond level, which is crucial to assess spatio-temporal dynamics within the deltas. Thus, high-resolution data is necessary to accurately map aquaculture ponds and quantify their size and shape, and especially to distinguish between single aquaculture ponds [27].

To cover the spatio-temporal requirements of aquaculture analyses, Landsat Surface Reflectance (SR) data and Sentinel-1 imagery are used to exploit the large potential of the open Landsat archive with multispectral satellite data spanning time periods of more than 30 years. With the focus on coastal aquafarms, the goal of this study is to estimate increases in aquaculture area and reveal the dynamics and possible hotspots of aquaculture expansion in coastal areas of two target deltas in China: the Yellow 
River Delta (YRD) and Pearl River Delta (PRD). The results of this study serve to demonstrate the potentials and limitations of aquaculture quantification through long-term Landsat imagery and highlight differences in the assessment among the case study regions.

Although the Landsat program provides data for long time periods, Landsat's spatial resolution of $30 \mathrm{~m}$ is a limiting factor for detecting small-scale features such as aquaculture ponds $[27,28]$. Therefore, this study combines the advantage of high spatial resolution Sentinel-1 data having a resampled spatial resolution of $10 \mathrm{~m}$ for precise aquaculture pond mapping with the temporal component of Landsat imagery for analyzing historical aquaculture patterns.

\section{Study Areas and Data}

\subsection{Study Areas}

The study area comprises the YRD and the PRD in China (Figure 1). The Yellow River has a comparatively low water flow, but transports the highest sediment loads worldwide, which originate in the country's Loess Plateau and supply the floodplains with valuable nutrients [29]. The delta region is characterized by rapid economic growth and urban expansion, both accompanied by heavy pollution [30-33]. In addition, groundwater extraction reaches alarming proportions, which are mainly caused by aquaculture, and the salt content exceeds that of seawater in some parts of the delta [18]. The PRD is highly populated and lies within the center of the Guangdong province. The delta includes mega-cities with a population of more than 10 million. The whole delta is undergoing enormous urbanization processes, and single cities tend to become one large interwoven urban complex [34,35]. Nonetheless, the majority of the population is still living in non-urban parts, and agriculture is a popular practice within the PRD. Heavy metal pollution originating from industry and aquaculture is a big concern, which is also evident in farmed aquatic species destined for food consumption [10]. The use of pharmaceuticals in aquaculture is further accelerating pollution processes [9]. Many coastal areas in China have to deal with heavy pollution, but the PRD exceeds the usual parameters [10].

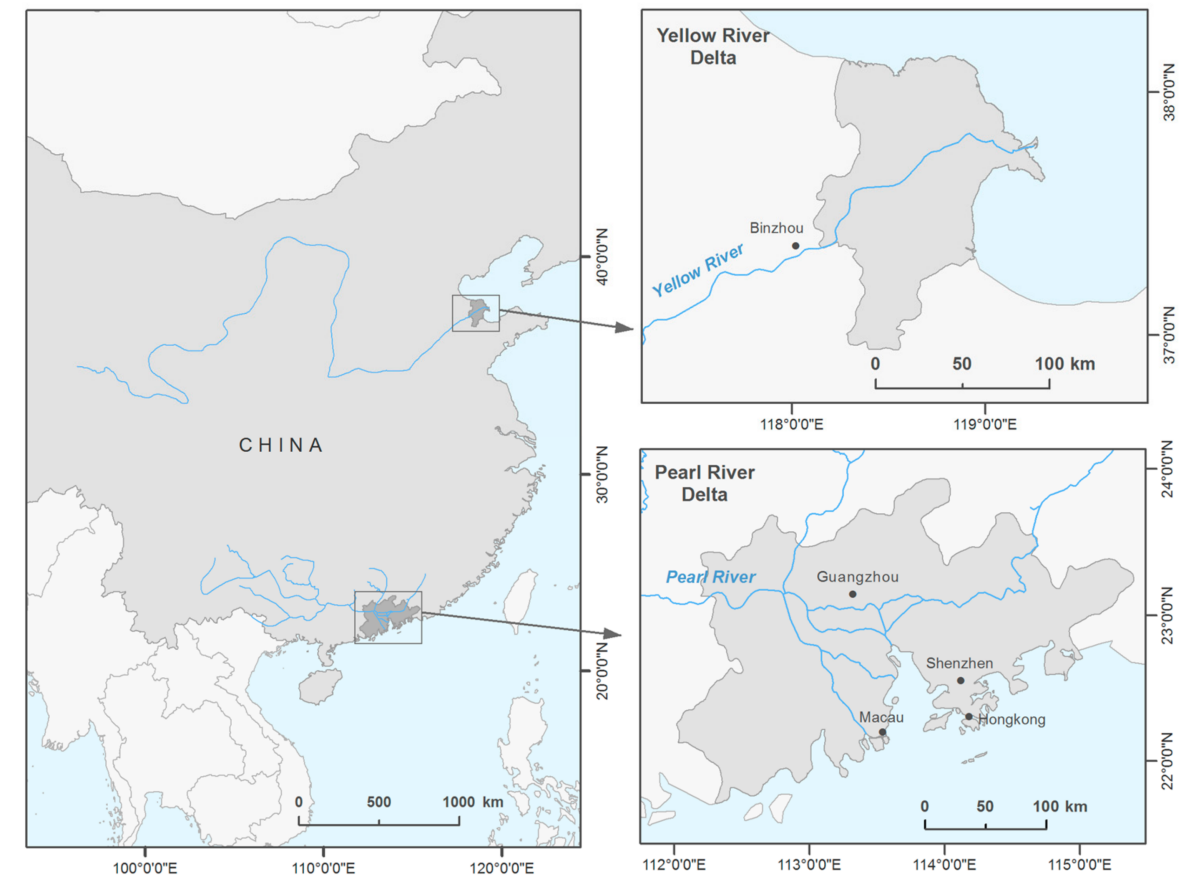

Figure 1. Map of the two investigated deltas.

Aquaculture has a long tradition in Asia and has undergone tremendous expansion-mainly along the coasts of China and its major river deltas. China, with $62 \%$ of total aquaculture production, 
is by far the world's largest producer of cultured aquatic organisms [1]. The Chinese provinces of Guangdong and Shandong - which include the YRD and PRD, respectively—contribute the highest shares to the national aquaculture volume produced in China, and our selected study sites are also one of the world's largest and most significant aquaculture production centers.

\subsection{Data}

This study uses a reference dataset with spatial explicit information on aquaculture ponds for the year 2015. The dataset covers both deltas, and was derived by the authors in a previous study [27] by exploiting Sentinel-1A time series acquired between September 2014 and September 2016. For the PRD and the YRD, a total of 174 and 66 Sentinel-1A data in the Interferometric Wide-Swath (IW) acquisition mode and Ground Range Detected High Resolution (GRDH) format were processed to obtain temporally smoothed time series. Terrain information derived from Shuttle Radar Topography Mission (SRTM) Version 3.0 Global 1 arc second dataset (SRTMGL1) digital elevation model (DEM) data and accurate coastline data provided by the Institute of Geographic Sciences and Natural Resources Research (IGSNRR) Chinese Academy of Sciences [36,37] were utilized to identify and mask potential aquaculture areas. An open source segmentation algorithm supported the object-based extraction of aquaculture ponds based on backscatter intensity, size, and exemplary features. The resulting layers in vector format contain the derived footprints of each extracted pond, and feature overall accuracy levels of $80 \%$ and $88 \%$ for the YRD and the PRD, respectively. When assessing aquaculture with Earth observation data, it is challenging to delineate between artificial and natural water surfaces, as they have similar spectral properties. We coped with this by using the Sentinel-1 derived aquaculture layer as a baseline for our analyses.

For the long-term analysis of aquaculture ponds, multispectral Level-2 Landsat SR data are used provided as an analysis ready data cube by the Google Earth Engine (GEE: https://earthengine.google. $\mathrm{com} /$ ) team, which co-locates a petabyte scale satellite data archive with vast processing capabilities [38]. The Level-2 Landsat SR data guarantee for atmospherically corrected surface reflectance following the principles of the Landsat Ecosystem Disturbance Adaptive Processing System (LEDAPS) for Landsat 5 and Landsat 7 imagery [39] and the Landsat Surface Reflectance Code (LaSRC) for Landsat 8 imagery [40]. Besides, the Landsat SR data contain the so-called CFmask band containing per-pixel quality information on land, water, cloud, and cloud shadow based on the Function of mask (Fmask) algorithm [41]. We used the CFmask band to perform cloudmasking. In total, 4032 Landsat SR scenes are processed in this study, of which $75 \%$ originate from Landsat 5 , followed by $8 \%$ and $17 \%$ originating from Landsat 7 and Landsat 8, respectively. For the YRD, a total of 1908 scenes are used, which are sufficient to generate cloud-free image composites for every year between 1984-2016 (Figure 2). For the PRD, a total of 2124 scenes are used to generate annual composites with gaps for the years 2010, 2012, and 2015 due to insufficient data coverage.

In addition, in this study, the GSW dataset was used to evaluate its suitability as a readily available water mask product for a potentially global scale application of this approach, and is used as an alternative to custom tailored water masks derived from the Landsat SR data archive for the two target deltas. Besides, we used the GSW dataset to assess natural water bodies for the first year of observation (see Section 3.1). It is a global raster dataset on inland water surfaces that consists of a variety of products containing data on global water dynamics and extents. It can be assessed through the GSW Explorer initiated by the European Commission's Joint Research Centre. For this study, the yearly history dataset is used, which is available via the GEE platform. It is based on Landsat Top of Atmosphere data, and is available from 1984 to 2015 [42]. 


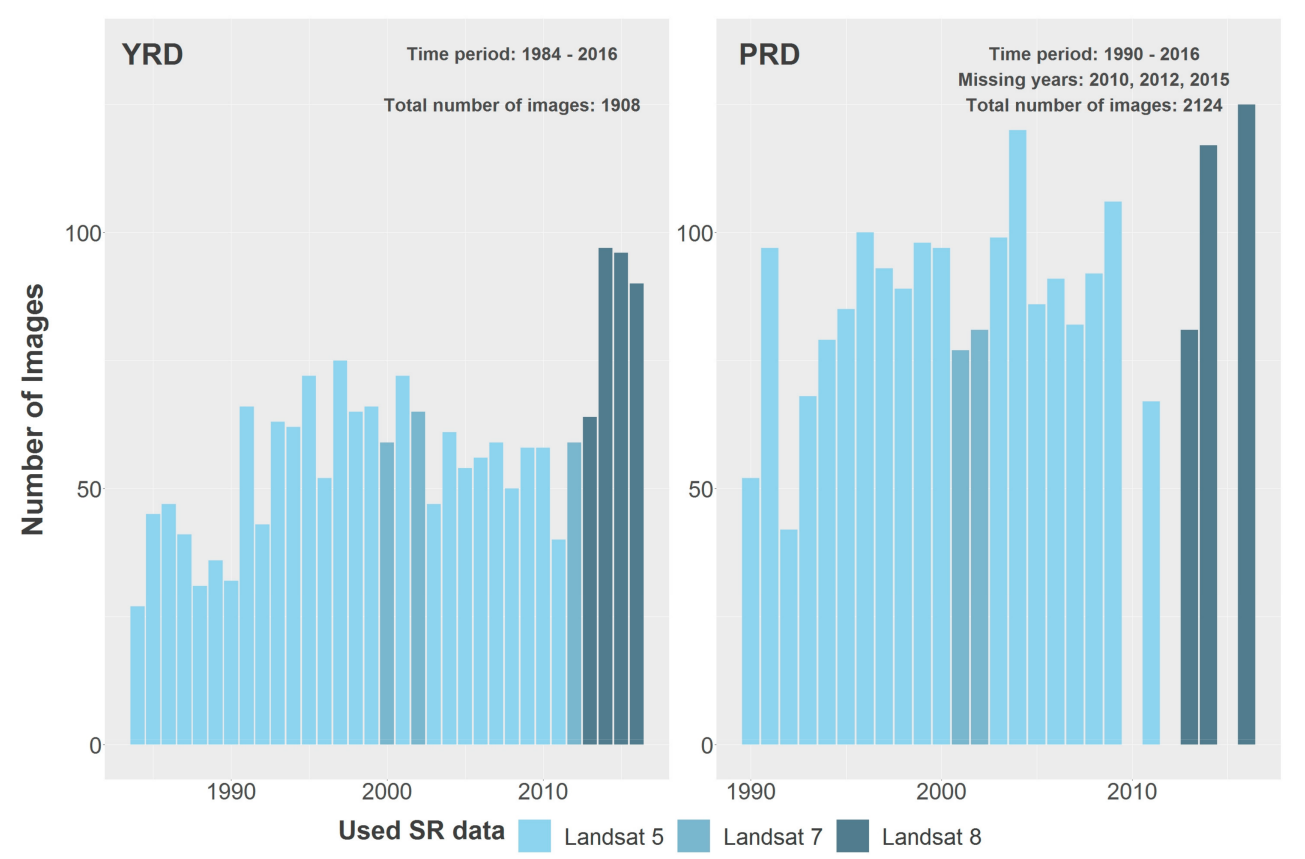

Figure 2. Available Level-2 Landsat SR data in the Yellow River Delta (YRD) and the Pearl River Delta (PRD), from 1984-2016.

\section{Methodology}

The method exploits the favorable characteristics of Sentinel-1 for high spatial resolution water body mapping together with the advantages of the Landsat archive for long-term analyses of land surface dynamics. First, Sentinel-1AB is used for the mapping of the current aquaculture extent at 10-m spatial resolution, which was already described in detail in [27]. Subsequently, the derived pond layer is used in combination with annual water masks derived from historic Landsat data. The approach is based on the assumption that (1) due to the continuous and rapid development of aquaculture worldwide, the current spatial extent of aquaculture ponds resembles the maximum status compared to previous years; and (2) that ponds identified for the reference year 2015 can be assumed to be ponds also in previous years when permanently filled with water in these years.

\subsection{Aquaculture Area Classification}

The annual water masks for each focus region are generated according to the following six steps (Figure 3). Firstly, for every target year, all the available Landsat images are selected, and cloud and cloud shadow masking is performed based on the CFmask band. Secondly, the Normalized Difference Water Index (NDWI) is calculated for every Landsat image using the green and near infrared (NIR) bands, according to [43], to better identify the water surfaces within the deltas. The third step focuses on calculating spectral-temporal features to exploit the temporal characteristics of aquaculture ponds for the classification process. Aquaculture ponds can be generally described as permanent water bodies [27], in contrast to e.g., temporarily inundated rice paddy fields, which are the main source of confusion in this approach. Therefore, temporal metrics, i.e., the 10th and the 90th percentiles are calculated at the pixel basis from all the cloud-free NDWI observations within the target year. The difference between the lowest (10th percentile) and the highest (90th percentile) stable NDWI values within the year serves as a good indicator for the persistence of inundation supporting the accurate differentiation between aquaculture and rice paddy fields [8]. Fourth, a threshold was defined to separate pixels attributed to land or water, which results in a binary mask separating permanent water surfaces from land areas. The threshold for every river delta was defined empirically by trial and error (Table A1), and was validated by interpreting high-resolution Google Earth imagery. In the fifth 
step, using the Sentinel-1 aquaculture pond layer from 2015 as a mask, the proportion of water area within each pond was quantified for each year based on the respective Landsat water mask. In the last step, we determined the final Landsat aquaculture layer. Therefore, ponds were filtered according to their amount of relative water coverage. Thereby, different thresholds were empirically tested using the Sentinel-1 aquaculture layer for 2015 in combination with high spatial resolution Google Earth imagery. For each year, only pond objects that had at least one-third of their surface area covered with water were retained as valid aquaculture ponds. The low threshold on relative water coverage can be explained by the spatial discrepancies resulting from the usage of different data sources (Synthetic Aperture Radar (SAR) versus multispectral) and their respective properties (30-m versus 10-m spatial resolution). As can be seen from Figure 4, it is evident that detected water surfaces and pond structures show generally corresponding patterns; however, they do not match perfectly to each other for the reasons mentioned above.

Permanent natural water bodies that are converted to aquaculture in later years are one source of error leading to overestimations of aquaculture. These water areas are generally identified as aquaculture throughout the entire observation period, regardless of their actual time point of conversion. Therefore, based on the GSW data, we retrieve annual water masks of the starting year of investigation for each delta assessed with Landsat SR data. We manually remove artificial water surfaces such as aquaculture ponds by visual interpretation with the help of high-resolution Google Earth imagery. These result in one layer per delta, representing the natural water body extent for the beginning of the observation period of each delta, i.e., 1984 for the YRD and 1990 for the PRD. For the latter, we mosaicked the yearly GSW data between 1990-1994 before creating the water mask. Based on these layers, we identify those natural water bodies for each delta that have been converted to aquaculture in later years during the observation period. The proportion of these erroneously identified ponds (false positives) in relation to all ponds can be used as an indicator for the degree of uncertainty related to this type of error.

Furthermore, to assess the suitability of the GSW water masks as a readily available substitute to the custom-tailored Landsat water masks, an additional aquaculture layer was generated for each year for which GSW data were available. This was done by replacing steps 1-4 with the annual water masks from the GSW dataset.

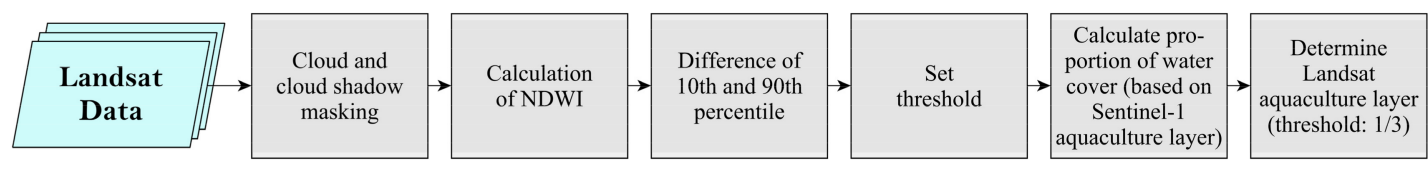

Figure 3. Workflow diagram on creating Landsat aquaculture layers and assessing aquaculture dynamics.

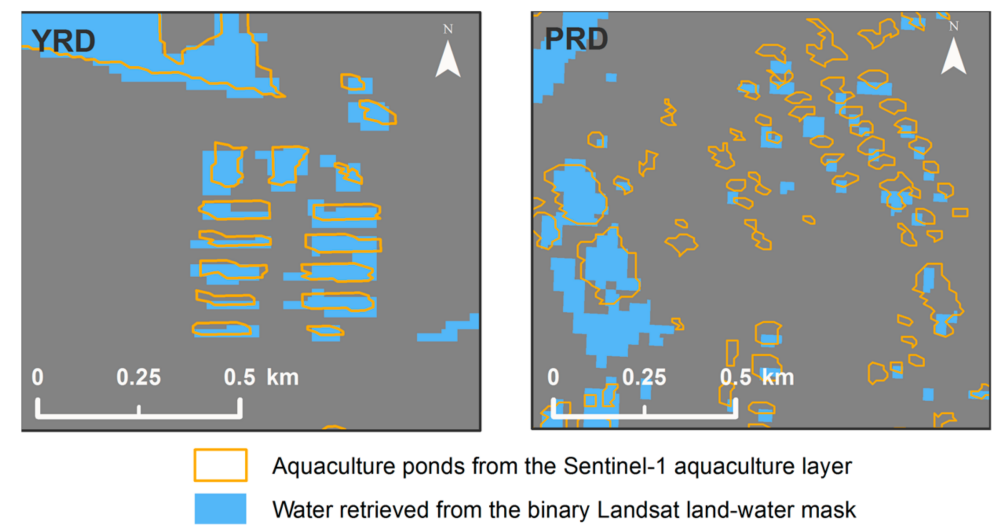

Figure 4. Detected permanent water bodies overlaid by the Sentinel-1 aquaculture layer for 2015. 


\subsection{Spatial Analysis}

To support additional spatial-temporal analyses of aquaculture patterns, a uniform hexagonal grid was defined for both deltas with a diameter of $4000 \mathrm{~m}$ for the inscribed circle, which allows cross-delta comparisons. Subsequently, aquaculture polygons were converted into point data and were distinctly assigned to the hexagon into which they fall. In this way, for each hexagonal cell, the number of aquaculture ponds and aquaculture area in square meters was aggregated for each year. To identify hotspot zones of aquaculture expansion and robustly quantify the increase in land consumption of the aquaculture sector, a linear regression analysis was conducted, whereby time (at annual intervals) is the explanatory variable, and the aquaculture area (in square meters) is the response variable. The regression analysis was undertaken for each hexagon of the delta landscape, which resulted in a total of 3346 individual regression models (494 for the YRD and 2852 for the PRD). We define hotspots as a hexagon with increasing aquaculture size during our observation period.

\subsection{Accuracy Assessment}

We collected reference data using high-resolution imagery available via Google Earth, which is a frequently used source for ground truth reference data in remote sensing studies [44]. The PRD serves as exemplary for validating the approach regarding assessing the temporal dynamics within the delta regions, since this delta showed the best coverage of high-resolution satellite data for different time points throughout the observation period. We examined available historic high-resolution imagery and collected suitable reference information for 2004, 2014, and 2015. We compared mapping results with reference data for two classes in order to robustly evaluate the approach focusing on aquaculture dynamics: (1) aquaculture ponds detected in the reference year 2015 that were also mapped as aquaculture in the evaluation years, i.e., the class stable aquaculture; and (2) aquaculture ponds detected in the reference year 2015 that have not been mapped as aquaculture in the remaining evaluation years, i.e., class aquaculture change. In total, we selected 60 aquaculture ponds for each class by random sampling evenly for all the years of evaluation. Finally, from the evaluation results, we calculated standard measures of accuracy, i.e., the producer's, the user's, and the overall accuracy as well as Cohen's kappa coefficient [45].

\section{Results}

\subsection{Accuracy Assessment of Aquaculture Area Classification}

A comparison of detected ponds against the Sentinel-1 reference mask for the year 2015 reveals the superiority of using the high spatial resolution Sentinel-1 SAR sensor (Table 1). Around $80 \%$ and $63 \%$ of aquaculture ponds in the YRD and the PRD respectively by the Sentinel-1 Aquaculture Layer could be detected by the combined approach with Landsat. When considering the aquaculture area, numbers increase to $95 \%$ for the YRD and $81 \%$ for the PRD, which indicates that agreement between the two approaches improves, particularly for large ponds.

Table 1. Comparison of detected aquaculture by [27] and our approach for the year 2015.

\begin{tabular}{ccc}
\hline & YRD & PRD \\
\hline Sentinel-1 Aquaculture Layer & & \\
\hline Number of ponds & 19,700 & 264,894 \\
Total aquaculture pond areas $\left(\mathrm{km}^{2}\right)$ & 828.6 & 1050.7 \\
\hline Landsat Aquaculture Layer & & \\
\hline Number of detected ponds & 15,270 & 169,194 \\
Number of detected ponds $(\%)$ & 80.1 & 63.9 \\
Total pond area detected $\left(\mathrm{km}^{2}\right)$ & 791.2 & 853.1 \\
Total pond area detected $(\%)$ & 95.5 & 81.2 \\
\hline
\end{tabular}


The absolute validation of mapping results for the PRD (see Table 2) reveals an overall accuracy of $89 \%$ and a kappa of 0.78 , which can be categorized as a substantial agreement between the mapped results and the reference data [46]. Particularly high was the producer's accuracy for stable aquaculture ponds. For the class stable ponds, 59 out of 60 were correctly identified as ponds for the reference year 2015 and the respective target year. However, only 48 out of 60 ponds were correctly classified as the class aquaculture change, i.e., existing ponds in the reference year 2015 that did not yet exist in the other evaluation years. Generally, producer's and users's accuracies are imbalanced for the two classes, resulting from an overestimation of stable aquaculture and an underestimation of the class aquaculture change.

Table 2. Accuracies and kappa obtained by the accuracy assessment for the PRD.

\begin{tabular}{cccccc}
\hline \multicolumn{2}{c}{ Producer's Accuracy } & \multicolumn{3}{c}{ User's Accuracy } \\
\hline stable aquaculture & aquaculture change & stable aquaculture & aquaculture change & Overall Accuracy & Kappa \\
98.3 & 80.0 & 83.1 & 98.0 & 0.78 & 89.0 \\
\hline
\end{tabular}

The evaluation of permanent natural water bodies for the YRD revealed that $6.7 \%$ of all ponds are identified as natural water surfaces, which coincides with $3.8 \%$ of the total aquaculture area (Table 3). For the PRD, 3.9\% of the aquaculture ponds are considered to be natural water, which corresponds to $7.9 \%$ of the aquaculture area.

Table 3. Assessment of natural water bodies within the target deltas.

\begin{tabular}{ccc}
\hline & YRD & PRD \\
\hline Number of Ponds (\%) & 6.7 & 3.9 \\
Area of Ponds (\%) & 3.8 & 7.9 \\
\hline
\end{tabular}

We found enormous increases in aquaculture area for both target deltas (Figure 5). Based on Landsat SR data, the minimum aquaculture area in the YRD occurred in 1984 with $42 \mathrm{~km}^{2}$, whereby the maximum is evident in 2015 with $779 \mathrm{~km}^{2}$. This reveals a total increase of $1856 \%$. Based on GSW data, the aquaculture area shows a total increase of $722 \%$. The annual increase of $22 \mathrm{~km}^{2}$ is equal for both the Landsat and the GSW data (Landsat SR data: adj. $R^{2}=0.95, p$-value $=<2.2 \times 10^{-16}$; GSW data set: adj. $R^{2}=0.91, p$-value $\left.=<2.2 \times 10^{-16}\right)$. We observe the overall minimum of aquaculture area for the PRD in 1991 with $187 \mathrm{~km}^{2}$. The annual increase in aquaculture area assessed with Landsat data is $25 \mathrm{~km}^{2}$ (adj. $\mathrm{R}^{2}=0.91, p$-value $=2.64 \times 10^{-10}$ ). Considering the aquaculture area for the PRD assessed with Landsat data, we found an increase of $406 \%$ with $207 \mathrm{~km}^{2}$ in 1990 and $839 \mathrm{~km}^{2}$ in 2016 $\left(\right.$ adj. $R^{2}=0.91, p$-value $\left.=2.64 \times 10^{-10}\right)$. Based on GSW data (adj. $R^{2}=0.75, p$-value $\left.=5.362 \times 10^{-7}\right)$, our findings revealed an overall increase of $279 \%$ from $241 \mathrm{~km}^{2}$ to $674 \mathrm{~km}^{2}$ in the period from 1988 to 2015. The annual increase is different for Landsat SR data and GSW, with $16 \mathrm{~km}^{2}$ and $25 \mathrm{~km}^{2}$, respectively. However, we identify a clear upward trend of aquaculture changes for both datasets. 


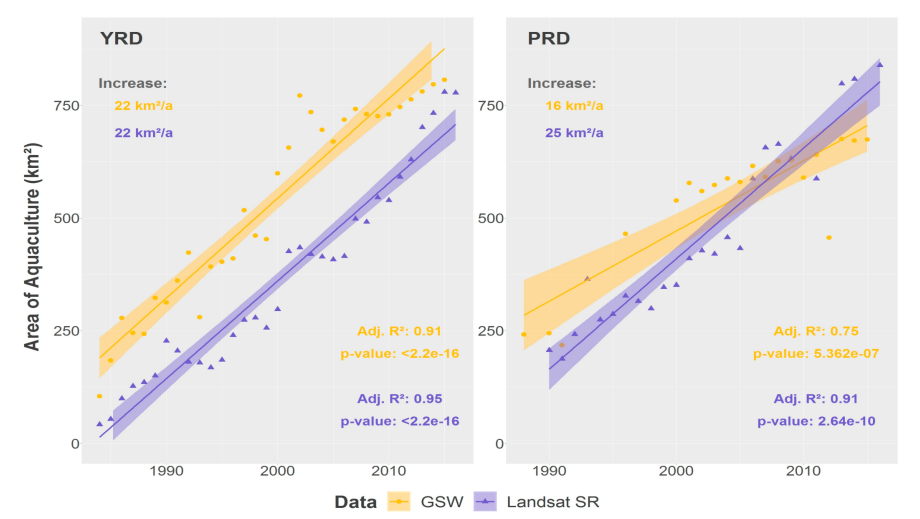

Figure 5. Trend in aquaculture area for the YRD and the PRD based on Global Surface Water (GSW) data and Landsat Surface Reflectance (SR) data with adjusted $\mathrm{R}^{2}$ and $\mathrm{p}$-value obtained from the regression analysis, including the $95 \%$ confidence region.

\subsection{Spatial Variations in Aquaculture Area}

Figure 6 depicts the spatial-temporal aquaculture dynamics for the YRD for the time period from 1984 to 2016. The dynamics of aquaculture for both deltas are visualized with a color palette from blue (early in time) to dark red (late in time) with a corresponding grading in color for each year (Figures 6 and 7). The size of the aquaculture ponds is comparatively large; the shape is predominantly elongated, but also squared. Within the whole delta, aquaculture concentrates in the coastal regions, in particular at the northern and southern coast. Some minor misclassifications occur for a small number of ponds, e.g., within the course of the river.

The aquaculture within the PRD (Figure 7) is characterized by small mean pond sizes. The map shows the dynamics of aquaculture for the time period from 1990 to 2016, but due to insufficient data coverage, the years 2010, 2012, and 2015 are not included in the analysis. The shape of the ponds is elongated or square-shaped. Most aquaculture ponds concentrate along the branches of the river or along the coast. The detailed extent within the map shows aquaculture at one of the river mouths within the delta. This spatial detail shows very clearly how aquaculture development gradually expanded from the coast toward inland within the course of the observation period.

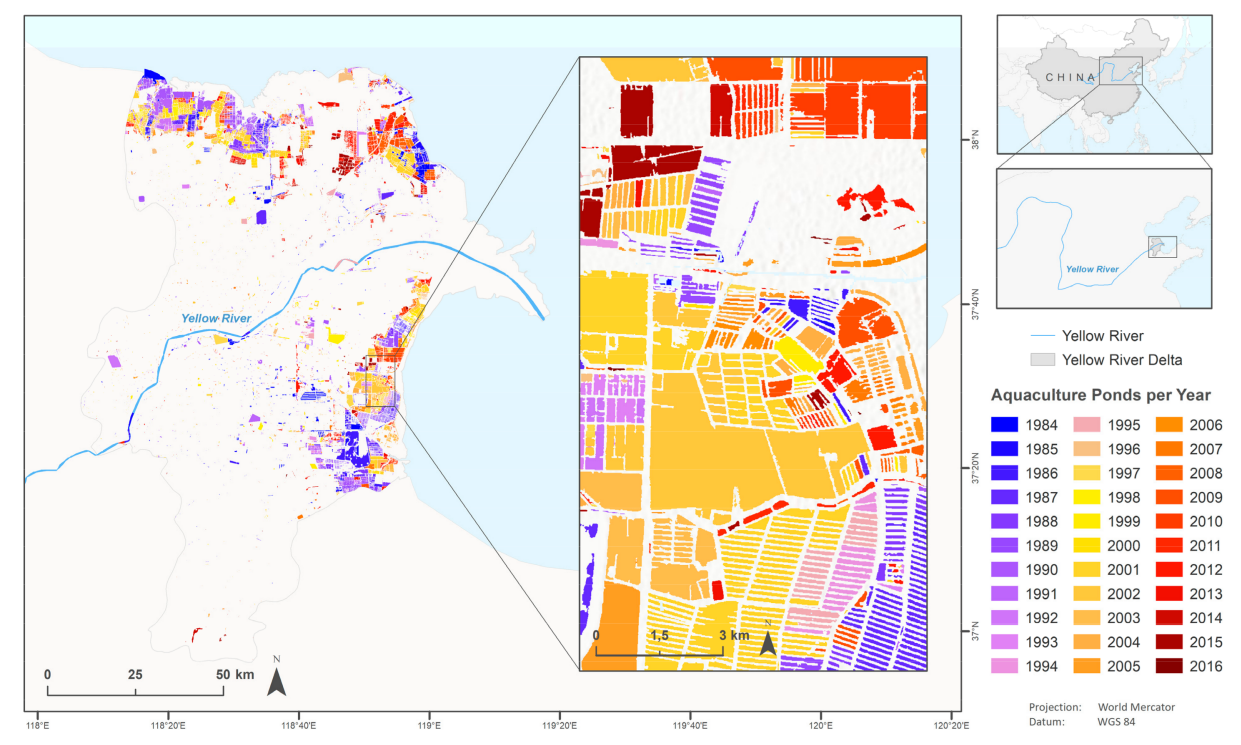

Figure 6. Aquaculture dynamics for the YRD from 1984 to 2016. 


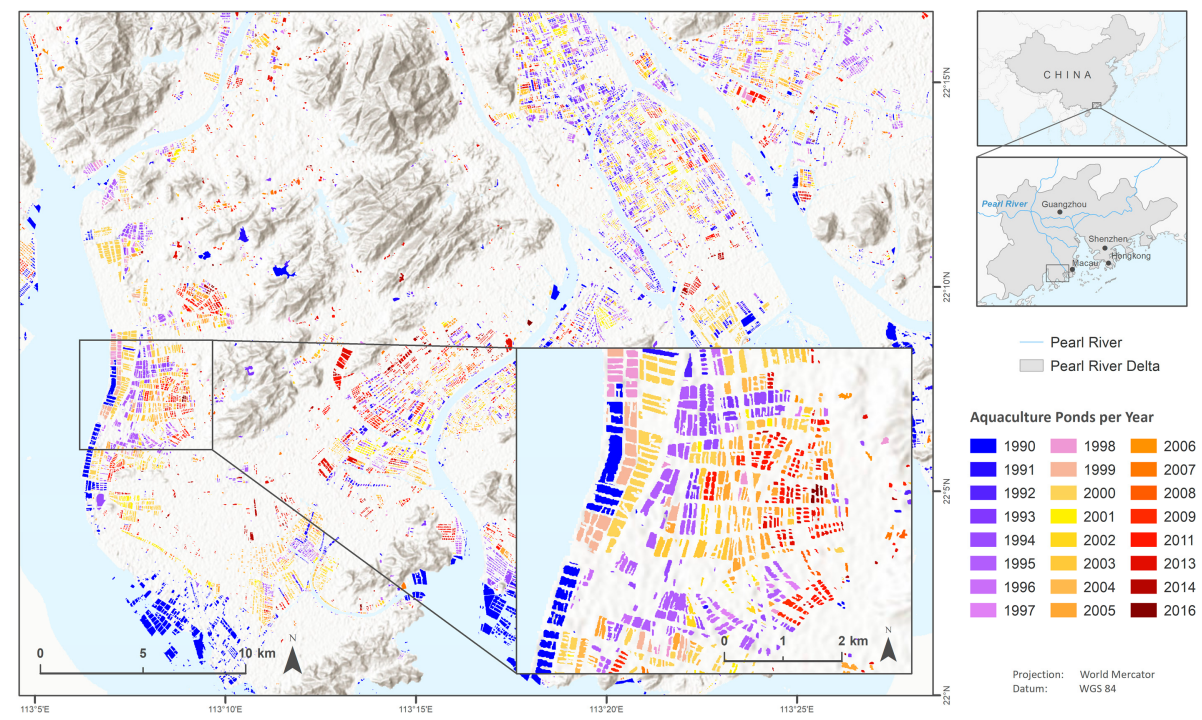

Figure 7. Aquaculture dynamics for the PRD from 1984 to 2016.

\subsection{Temporal Patterns And Hotspots}

We carried out a spatial explicit regression analysis based on a hexagon landscape to reveal aquaculture patterns over time and identify hotspot areas (Figures 8 and 9). The maps reveal the trend of aquaculture development for the observed time period and for each $4000 \mathrm{~m}$ hexagon within the delta landscape (each hexagon area corresponds to approximately 13 million $\mathrm{m}^{2}$ ). For areas without aquaculture, no hexagons where generated. The observed trends are divided into four classes: (1) increase in aquaculture area, (2) decrease in aquaculture area, (3) no observed trend, or (4) no significant change ( $p$-value $\leq 0.05$ ). Additionally, we grouped the average annual increase in area of aquaculture (class 1) according to the slope values retrieved from the regression analysis. The division into classes was made according to the Jenks' Natural Breaks algorithm [47], and the resulting values were rounded for reasons of clarity.

We divided the YRD into a total of 494 hexagons (Figure 8). Only $1.0 \%$ of the hexagons show a decrease in aquaculture area, and 9.7\% reveal no significant trend. For $89.4 \%$, we observe an increase in aquaculture area from 1984 to 2016 . For approximately $63.0 \%$ of all hexagons, the aquaculture increase is $<30,000 \mathrm{~m}^{2}$. A total of $8.5 \%$ of the hexagons are characterized by high $\left(180,000-290,000 \mathrm{~m}^{2}\right)$ and very high $\left(>290,000 \mathrm{~m}^{2}\right)$ increases per year. Considering the spatial distribution of these two classes and the medium increase class $\left(90,000-180,000 \mathrm{~m}^{2}\right)$, major increases in aquaculture area are present at the coastline of the delta, and major decreases are present within the central southern part of the delta. 


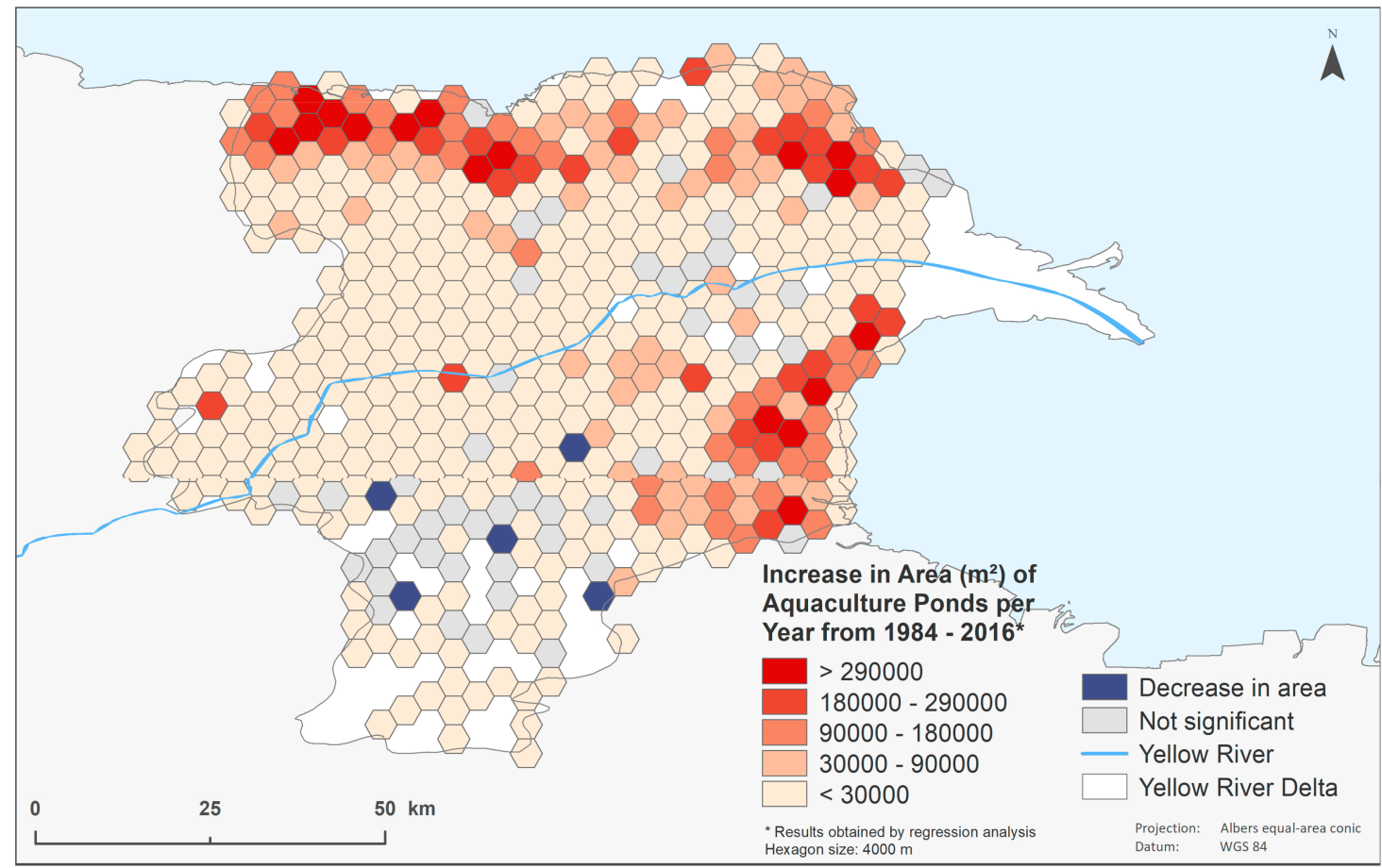

Figure 8. Temporal patterns and hotspots of aquaculture expansion for the YRD.

The PRD is divided into a total of 2852 hexagons (Figure 9). No significant trend is present for $15.8 \% ; 1.4 \%$ reveals a declining trend in regard to aquaculture area, and for $0.1 \%$, no trend is apparent. The parts of the delta for which we observe a decrease are mainly located at the coastline or on offshore islands of the region. We observe an increase in aquaculture area from 1990 to 2016 for $82.7 \%$ of the hexagons. The high-area increase classes $\left(40,000-80,000 \mathrm{~m}^{2}\right.$ and $\left.>80,000 \mathrm{~m}^{2}\right)$ are mostly located close to the Pearl River and at some areas along the west coast of the delta.

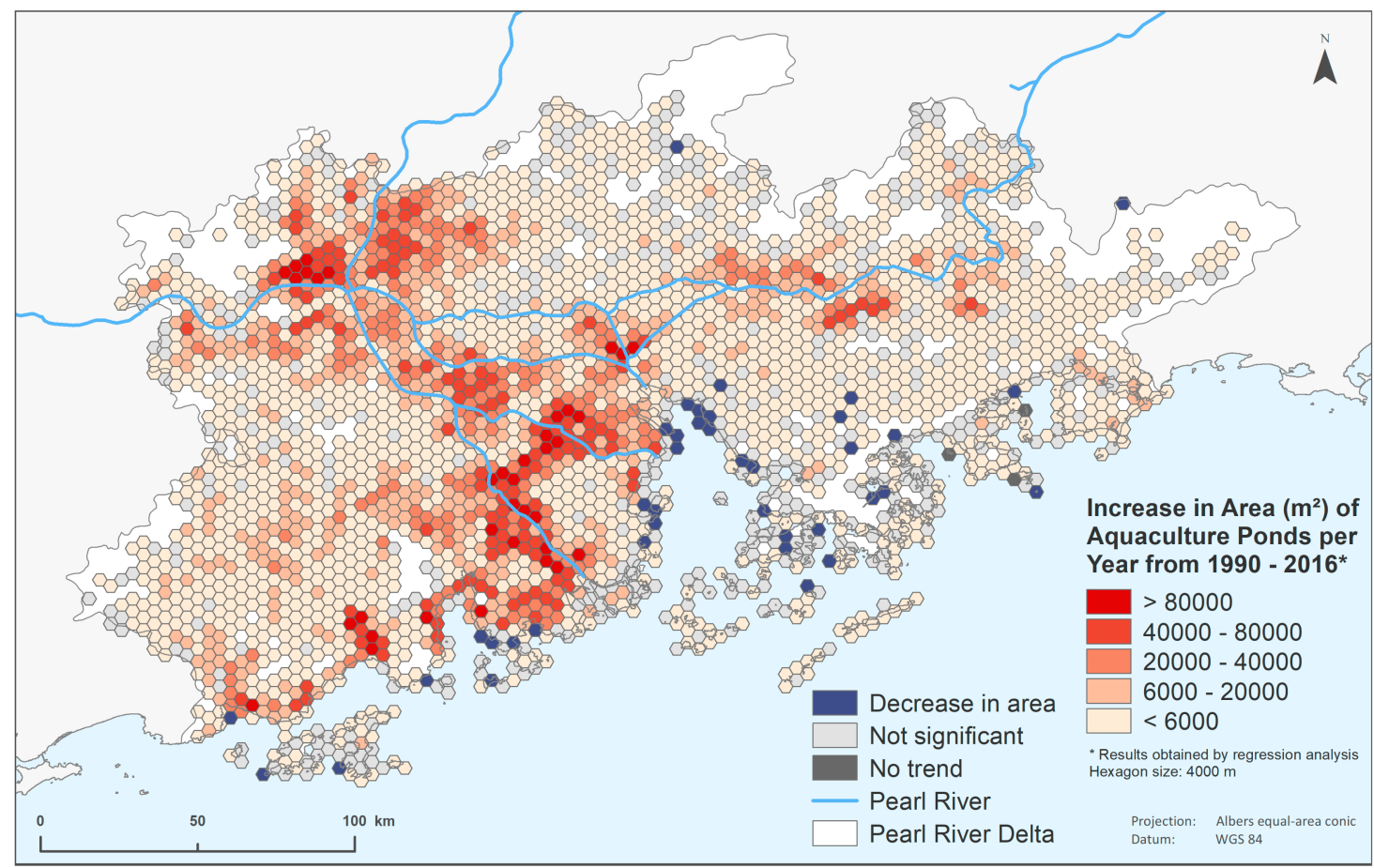

Figure 9. Temporal patterns and hotspots of aquaculture expansion for the PRD. 


\section{Discussion}

\subsection{Increase in Aquaculture Area}

One major aim of this study was to investigate the change in aquaculture area within the observed time period for two Chinese deltas: the YRD and the PRD. Our findings reveal an expansion in aquaculture area for both deltas based on Landsat SR and GSW data.

We detect the highest relative and total increase for the YRD (a 18.6-fold increase in aquaculture area from 1984-2016). This is in accordance with findings showing that the Shandong province is the main aquaculture producer along China's coastal regions [48]. Aquaculture is a major expanding land-cover type within the YRD $[18,31]$. Another factor that might contribute to aquaculture expansion is the large size of single aquaculture ponds within the $Y R D$, which adds a high amount of aquaculture area per year caused by comparatively few additional ponds. The size of aquaculture ponds also supports that the aquaculture production in the YRD is rather commercial than on the small household or subsistence scale [49]. The GSW results reveal a 7.1-fold increase in area (1984-2015) for the YRD; thereby, increases in aquaculture area are considerably lower. Water areas might be overestimated for the beginning of the observation period, which would cause the overall increase in aquaculture area to be lower. Both datasets reveal the same annual increase in aquaculture area with $22 \mathrm{~km}^{2}$, indicating a good correspondence between the two data sets for the YRD. However, our findings reveal that aquaculture area is higher when using GSW data throughout the entire observation period. A main reason for this is that we observed large areas at the coast to be identified as water, e.g., seasonally flooded land-cover types such as wetlands and floodplains. By manually defining thresholds, this observation was not present for the tailor-made water masks, and the overall aquaculture area results were lower.

For the PRD, we found a 4.1-fold increase based on Landsat data, and a 2.8-fold increase based on the GSW data set. The magnitude of aquaculture expansion is again lower for the assessment with GSW data, and can be justified based on the assumptions made in the previous paragraph. The increase in aquaculture area is relatively low for the PRD when compared to the findings for the YRD. This might be caused by rapid urban growth within the Pearl Delta region. In the past decades, a major part of the delta's former agriculture area has been turned into building land for real estate and industry [50,51]. As a consequence, it is no longer available for aquaculture production. Besides, the PRD became the biggest urban region in size and population [52], and urban density increased during the last decades [35], which rather promotes urbanization than increases in aquaculture for some parts of the delta. Although the total increase in aquaculture area is lower for the PRD, its expansion in area of $632 \mathrm{~km}^{2}$ (Landsat SR data) and $279 \mathrm{~km}^{2}$ (GSW dataset) is considerable. This leads to the conclusion that aquaculture is still maintaining and increasing, even in one of the most populated urban region worldwide such as the PRD. The annual increase in aquaculture area of approximately $25 \mathrm{~km}^{2}$ (Landsat SR data) and $16 \mathrm{~km}^{2}$ (GSW data set) reveals dissimilar results, with a 9-km² higher annual increase in aquaculture area by using Landsat SR data. One possible reason might be the small aquaculture pond size in the PRD, whereby tailor-made water masks based on annual Landsat SR data are more suitable to be used than the readily available GSW products. Additionally, aquaculture area retrieved from Landsat data reveals more consistent and robust results (adj. $R^{2}$ : 0.91) than the GSW data-based analysis (adj. $R^{2}$ 0.75) within the PRD. The total aquaculture area assessed with GSW data is higher at the beginning of the observation period, and is lower from 2007 onwards. This pattern also supports that (1) water surfaces are overestimated within the GSW dataset when aiming to detect aquaculture, and (2) smaller aquaculture ponds are better detected by using manually created water masks. Therefore, the applicability of the GSW dataset is different for both deltas. However, based on our results, trends and annual increases are similar, which is promising for using the GSW data for a global aquaculture analysis.

To conclude, aquaculture dynamics are characterized by notable expansions of aquaculture area within the observed time period. From an economic point of view, an increase in aquaculture is likely to be followed by economic growth [53], a decrease in poverty [2,3], and an increase in welfare 
on the individual basis [4]. From a nature conservation point of view, increases in aquaculture area are linked with the increasing ecological vulnerability of the delta regions ranging from salinization [54] over pollution $[5,9,30]$ to wetland change and mangrove removal [55-57]. We found the following. (1) The increase in aquaculture varies in terms of magnitude among the two deltas. (2) Aquaculture pond structures, e.g., pond size, have substantial differences for the investigated deltas. In addition, the study areas have different environmental geographical characteristics. In tropical and subtropical coastal regions, the clear-cutting of coastal forest (mainly mangrove forests) is a major environmental impact [57]. This can be attributed to the rapid development of aquaculture in many regions, among other human-induced land-use changes. The PRD is located in a subtropical climate, and the rapid socioeconomic development, along with the development of aquaculture, rice agriculture, and urbanization has caused a large-scale loss of coastal ecosystems, e.g., mangrove areas. The YRD encloses one of the largest wetlands in China, and oil exploration and aquaculture activities along its coastal zone has led to a large-scale loss of valuable salt marshes and reed belts during the past decade [58]. These facts emphasize why aquaculture management requires tailor-made conservation strategies.

\subsection{Dynamics And Hotspots of Aquaculture}

For both deltas, our results reveal clear hotspot patterns of aquaculture expansion (Figures 8 and 9). We expected hotspots to be located at the coast and along the river course of the deltas, which was mainly due to an easy water supply. Our findings support this hypothesis, although with remarkable differences among the two deltas.

We found hotspots of aquaculture expansion within the YRD predominantly along the coast. This is in accordance with findings from [31], who found increases in cultivated aquatic surfaces primarily in coastal areas. Additionally, the authors stated that aquaculture expansion is characterized by a coastward movement with the strongest increases in area within $35 \mathrm{~km}$ from the coastline in 2010, which coincides with the results of our study. Aquaculture is often located in coastal areas, as coasts provide easy access to water resources, and they belong to low-lying regions, which are favorable for aquaculture production [59]. Our results reveal a decrease in aquaculture area in the central southern part of the delta, mainly between the two cities Dongying and Guangrao. Especially, Dongying has transferred from a small village to a hotspot of oil industry [60], also promoting economic development, and consequently urban growth $[60,61]$. The authors of [62] found an urban growth rate of roughly 62\% from 2007 to 2013 for parts of Dongying city.

On the contrary, for the PRD, the hotspots of aquaculture increase are located along the course of the river (Figure 9). In the PRD, aquaculture is traditionally located along the river, as farmers can easily fill ponds with freshwater from the river [63]. Consequently, this pattern is still apparent, and the findings assume that additional aquafarms have been created along the Pearl River during the observation period. Simultaneously, several areas along the coast show a decrease in aquaculture from 1990 to 2016. This might be a consequence of urban land expansion, as the PRD is characterized by major industrial and urban growth [34], as well as increases in urban density [35]. The urban dynamics of the PRD are of unique intensity and morphology, thereby creating novel settlement types: mega-regions [35,64].

To sum up, we found hotspots of aquaculture expansion to be mainly located along the coast (YRD) and rivers (PRD). This revealed pattern is hazardous, as waste water is often discharged without treatment in aquaculture production [8]. Therefore, it can be assumed that an increase in aquaculture production in the investigated deltas is contributing to a deterioration of water quality. Urban and industrial activities cause additional water pollution with heavy metals [15], water quality is especially poor in Chinese delta regions [10,30,32]. As water for aquaculture farming is mainly withdrawn from the Pearl River, the polluted water within the aquaculture ponds is absorbed by the farmed aquatic species, and heavy metals can be detected in cultured fish $[16,65]$. Heavy metal contamination is even 
considered as a public health concern [10]. Therefore, our results give an impression of why such measured values and impurities with heavy metals occur.

\subsection{Potentials And Limitations of This Study}

We use Landsat SR data to identify the spatio-temporal dynamics of aquaculture over the last decades. However, optical satellite data are vulnerable to the effects of clouds, and thus are restricted for applications in cloud-prone areas [66]. High cloud coverage influences the quality of annual composites in this study, which might be an explanation for the annual fluctuations within the results for the aquaculture area. Therefore, data quality and availability are the major constraints of this study.

Another limitation for detecting the water areas of aquaculture with Landsat imagery is the coarse spatial resolution of $30 \mathrm{~m}$. A high proportion of aquaculture ponds from the Sentinel-1 aquaculture layer is not detected based on Landsat SR data. Therefore, the aquaculture area might even be considerably higher than that observed by our study. Furthermore, the outcomes of the accuracy assessment show that aquaculture ponds often fail to be detected for the past years. A major reason to be named is the coarse spatial resolution of Landsat imagery, as large ponds in the YRD are more suitable for being detected than the smaller aquaculture ponds of the PRD. Therefore, aquaculture characterized by bigger ponds is more likely to be detected than aquaculture consisting of rather small ponds. That might also be caused by pixel-mixing effects [67], which make it difficult to identify smaller aquaculture ponds.

In addition, our approach neglects natural waters that have been turned into aquaculture during the observation period. Especially along the coasts of the PRD, additional aquaculture ponds have been built in natural coastal floodplains, in the sea-by extending the coastline-or in inland waters. However, we quantified this error by assessing natural water bodies for the first years of observation (1984 for the YRD and 1990 for the PRD). The results show that this effect does matter for aquaculture within the observed target deltas, but does not majorly affect our findings. However, we suggest eliminating natural waters before assessing changes in aquaculture in further research. One option is to manually extract them based on the GSW dataset. Another option is to apply the presented approach by [68], which is based on feature extraction methods using Landsat imagery enabling the separation of aquaculture from other water features. However, it is questionable that this can accurately be performed for single aquaculture ponds solely based on Landsat data, and requires imagery with higher spatial resolution [27].

Besides the stated limitations of this study, an overall accuracy of $89 \%$ was shown, revealing a thorough accuracy for the presented approach. Furthermore, the spatio-temporal dynamics and patterns of aquaculture of two river deltas have been detected, also highlighting similarities and differences among the deltas. The approach itself can be applied on larger spatial scales, either by using Landsat SR data or with the help of global datasets such as the used GSW product. The approach is not site-specific; therefore, it is suitable for being used in other target regions. We revealed aquaculture structures and dynamics that also have specific management implications and help local authorities adapt their strategies to balance aquaculture production and conservation efforts based on location, size, and hotspot patterns. For example, large aquaculture pond sizes reflect intensified and commercial aquaculture production [8]. For shrimp farming, two general scenarios for sustainable shrimp aquaculture exist [69]. These are designed for either small-scale producers or industrial scale producers [69], which could be applied based on the revealed delta-specific conditions. We demonstrated that objective measurements and analysis of aquaculture dynamics can be realized by using remote sensing methodologies, not relying on other data sources.

\section{Conclusions}

Our findings reveal strong increases in aquaculture area for both deltas: the YRD and the PRD. Both deltas belong to the top aquaculture producers in China. Thus, our results can serve as exemplary for other coastal regions in Asia, and highlight the importance of assessing aquaculture objectively at 
large scales. As Asia has become the leading global aquaculture producer, contributing almost $90 \%$ of the global quantity, further increases in aquaculture area have to be expected in China and Asia in general. This is particularly hazardous for the sensitive coastal ecosystems, as many environmental consequences of aquaculture expansion are already present and are likely to intensify in the future. Based on the investigated deltas, the findings of this study suggest that aquaculture expansion is not following equal spatio-temporal dynamics. Therefore, unique management efforts need to be elaborated to guarantee human well-being and ecosystem functioning.

We combined Sentinel-1 derived aquaculture layers with Landsat data to guarantee the precise mapping of the aquaculture ponds, and opened the possibility of exploiting the long-term data availability of the Landsat fleet. Subsequently, we suggest using a combination of radar and Landsat satellite data to robustly map the spatio-temporal dynamics of aquaculture.

Following up the results of this study, an assessment for the complete Asian coast would be the next step in further research. Based on this, the detection of spatio-temporal dynamics for the coastal areas would not be restricted to single delta regions, but rather show aquaculture development for the entire coastline of Asia. Therefore, similarities and differences of delta versus non-delta regions could be retrieved, also highlighting the strongest increases in aquaculture area over time along the Asian coasts, and revealing possible indicators for the development of aquaculture expansions and dynamics. This could also be compared for conservation areas versus non-conservation areas or wetland areas versus non-wetland areas, which would have valuable implications for the management of coastal regions across Asia.

Author Contributions: Conceptualization, D.S. and P.L.; methodology, D.S. and M.O.; validation, D.S.; writing—original draft preparation, D.S.; writing—review and editing, D.S., M.O. and P.L.; visualization, D.S.; supervision, M.O. and P.L.

Funding: This research was partially funded by the German Ministry of Education and Research (BMBF) through the Catch-Mekong Project.

Acknowledgments: We thank the anonymous reviewers for the comments and advise that greatly improved the manuscript.

Conflicts of Interest: The authors declare no conflict of interest.

\section{Appendix A}

Table A1. Overview of thresholds that were manually assessed.

\begin{tabular}{|c|c|c|c|c|c|c|c|c|c|c|c|c|c|c|c|c|c|}
\hline Year & 2016 & 2015 & 2014 & 2013 & 2012 & 2011 & 2010 & 2009 & 2008 & 2007 & 2006 & 2005 & 2004 & 2003 & 2002 & 2001 & 2000 \\
\hline YRD & 0.15 & 0.13 & 0.12 & 0.15 & 0.15 & 0.05 & 0.15 & 0.10 & 0.15 & 0.10 & 0.10 & 0.08 & 0.10 & 0.15 & 0.10 & 0.11 & 0.10 \\
\hline PRD & -0.10 & 0.00 & -0.10 & -0.10 & 0.00 & 0.00 & 0.00 & 0.00 & 0.00 & -0.05 & 0.00 & 0.00 & 0.02 & 0.03 & 0.02 & 0.02 & 0.04 \\
\hline Year & 1999 & 1998 & 1997 & 1996 & 1995 & 1994 & 1993 & 1992 & 1991 & 1990 & 1989 & 1988 & 1987 & 1986 & 1985 & 1984 & \\
\hline YRD & 0.10 & 0.07 & 0.05 & 0.07 & 0.08 & 0.10 & 0.07 & 0.08 & 0.06 & 0.05 & 0.10 & 0.10 & 0.08 & 0.10 & 0.06 & 0.07 & \\
\hline PRD & 0.03 & 0.05 & 0.03 & 0.05 & 0.05 & 0.05 & 0.00 & 0.00 & 0.03 & 0.03 & & & & & & & \\
\hline
\end{tabular}

\section{References}

1. FAO. The State of World Fisheries and Aquaculture; FAO: Rome, Italy, 2016.

2. IrZ, X.; Stevenson, J.R.; Tanoy, A.; Villarante, P.; Morissens, P. The equity and poverty impacts of aquaculture: Insights from the Philippines. Dev. Policy Rev. 2007, 25, 495-516. [CrossRef]

3. Kaliba, A.R.; Ngugi, C.C.; Mackambo, J.M.; Osewe, K.O.; Senkondo, E.; Mnembuka, B.V.; Amisah, S. Potential effect of aquaculture promotion on poverty reduction in Sub-Saharan Africa. Aquac. Int. 2007, 15, 445-459. [CrossRef]

4. Pant, J.; Barman, B.K.; Murshed-E-Jahan, K.; Belton, B.; Beveridge, M. Can aquaculture benefit the extreme poor? A case study of landless and socially marginalized Adivasi (ethnic) communities in Bangladesh. Aquaculture 2014, 418, 1-10. [CrossRef] 
5. Herbeck, L.S.; Unger, D.; Wu, Y.; Jennerjahn, T.C. Effluent, nutrient and organic matter export from shrimp and fish ponds causing eutrophication in coastal and back-reef waters of NE Hainan, tropical China. Cont. Shelf Res. 2013, 57, 92-104. [CrossRef]

6. Ottinger, M.; Clauss, K.; Kuenzer, C. Opportunities and Challenges for the Estimation of Aquaculture Production Based on Earth Observation Data. Remote Sens. 2018, 10, 1076. [CrossRef]

7. FAO. The State of World Fisheries and Aquaculture; FAO: Rome, Italy, 2018.

8. Ottinger, M.; Clauss, K.; Kuenzer, C. Aquaculture: Relevance, distribution, impacts and spatial assessments-A review. Ocean Coast. Manag. 2016, 119, 244-266. [CrossRef]

9. He, Z.; Cheng, X.; Kyzas, G.Z.; Fu, J. Pharmaceuticals pollution of aquaculture and its management in China. J. Mol. Liq. 2016, 223, 781-789. [CrossRef]

10. Liang, P.; Wu, S.C.; Zhang, J.; Cao, Y.; Yu, S.; Wong, M.H. The effects of mariculture on heavy metal distribution in sediments and cultured fish around the Pearl River Delta region, south China. Chemosphere 2016, 148, 171-177. [CrossRef]

11. Wang, S.; Tang, D.; He, F.; Fukuyo, Y.; Azanza, R.V. Occurrences of harmful algal blooms (HABs) associated with ocean environments in the South China Sea. Hydrobiologia 2007, 596, 79-93. [CrossRef]

12. Keesing, J.K.; Liu, D.; Fearns, P.; Garcia, R. Inter- and intra-annual patterns of Ulva prolifera green tides in the Yellow Sea during 2007-2009, their origin and relationship to the expansion of coastal seaweed aquaculture in China. Mar. Pollut. Bull. 2011, 62, 1169-1182. [CrossRef]

13. Lee, J.H.; Pang, I.C.; Moon, I.J.; Ryu, J.H. On physical factors that controlled the massive green tide occurrence along the southern coast of the Shandong Peninsula in 2008: A numerical study using a particle-tracking experiment. J. Geophys. Res. 2011, 116. [CrossRef]

14. Son, N.T.; Chen, C.F.; Chang, N.B.; Chen, C.R.; Chang, L.Y.; Thanh, B.X. Mangrove mapping and change detection in Ca Mau Peninsula, Vietnam, using Landsat data and object-based image analysis. IEEE J. Sel. Top. Appl. Earth Obs. Remote Sens. 2015, 8, 503-510. [CrossRef]

15. Van, T.N.; Ozaki, A.; Tho, H.N.; Duc, A.N.; Thi, Y.T.; Kurosawa, K. Arsenic and heavy metal contamination in soils under different land use in an estuary in Northern Vietnam. Int. J. Environ. Res. Public Health 2016, 13, 1091.

16. Cheng, Z.; Man, Y.B.; Nie, X.P.; Wong, M.H. Trophic relationships and health risk assessments of trace metals in the aquaculture pond ecosystem of Pearl River Delta, China. Chemosphere 2013, 90, 2142-2148. [CrossRef] [PubMed]

17. Ha, T.P.; Dieperink, C.; Tri, V.P.D.; Otter, H.S.; Hoekstra, P. Governance conditions for adaptive freshwater management in the Vietnamese Mekong Delta. J. Hydrol. 2018, 557, 116-127. [CrossRef]

18. Higgins, S.; Overeem, I.; Tanaka, A.; Syvitski, J.P.M. Land subsidence at aquaculture facilities in the Yellow River delta, China. Geophys. Res. Lett. 2013, 40, 3898-3902. [CrossRef]

19. Pauly, D.; Zeller, D. Comments on FAOs state of world fisheries and aquaculture (SOFIA 2016). Mar. Policy 2017, 77, 176-181. [CrossRef]

20. Garibaldi, L. The FAO global capture production database: A six-decade effort to catch the trend. Mar. Policy 2012, 36, 760-768. [CrossRef]

21. Alonso-Pérez, F.; Ruiz-Luna, A.; Turner, J.; Berlanga-Robles, C.A.; Mitchelson-Jacob, G. Land cover changes and impact of shrimp aquaculture on the landscape in the Ceuta coastal lagoon system, Sinaloa, Mexico. Ocean Coast. Manag. 2003, 46, 583-600. [CrossRef]

22. Béland, M.; Goïta, K.; Bonn, F.; Pham, T.T.H. Assessment of land-cover changes related to shrimp aquaculture using remote sensing data: A case study in the Giao Thuy District, Vietnam. Int. J. Remote Sens. 2006, 27, 1491-1510. [CrossRef]

23. Rajitha, K.; Mukherjee, C.K.; Chandran, R.V.; Mohan, M.M.P. Land-cover change dynamics and coastal aquaculture development: A case study in the East Godavari delta, Andhra Pradesh, India using multi-temporal satellite data. Int. J. Remote Sens. 2010, 31, 4423-4442. [CrossRef]

24. Berlanga-Robles, C.A.; Ruiz-Luna, A.; Bocco, G.; Vekerdy, Z. Spatial analysis of the impact of shrimp culture on the coastal wetlands on the Northern coast of Sinaloa, Mexico. Ocean Coast. Manag. 2011, 54, 535-543. [CrossRef]

25. Bui, T.D.; Maier, S.W.; Austin, C.M. Land cover and land use change related to shrimp farming in coastal areas of Quang Ninh, Vietnam using remotely sensed data. Environ. Earth Sci. 2013, 72, 441-455. [CrossRef] 
26. Peneva-Reed, E. Understanding land-cover change dynamics of a mangrove ecosystem at the village level in Krabi Province, Thailand, using Landsat data. Giscience Remote Sens. 2014, 51, 403-426. [CrossRef]

27. Ottinger, M.; Clauss, K.; Kuenzer, C. Large-scale assessment of coastal aquaculture ponds with Sentinel-1 time series data. Remote Sens. 2017, 9, 440. [CrossRef]

28. Phiri, D.; Morgenroth, J. Developments in Landsat land cover classification methods: A review. Remote Sens. 2017, 9, 967. [CrossRef]

29. Ren, M. Sediment discharge of the Yellow River, China: Past, present and future-A synthesis. Acta Oceanol. Sin. 2015, 34, 1-8. [CrossRef]

30. Li, X.; Mander, Ü.; Ma, Z.; Jia, Y. Water quality problems and potential for wetlands as treatment systems in the Yangtze River Delta, China. Wetlands 2009, 29, 1125-1132. [CrossRef]

31. Ottinger, M.; Kuenzer, C.; Liu, G.; Wang, S.; Dech, S. Monitoring land cover dynamics in the Yellow River Delta from 1995 to 2010 based on Landsat 5 TM. Appl. Geogr. 2013, 44, 53-68. [CrossRef]

32. Wohlfart, C.; Kuenzer, C.; Chen, C.; Liu, G. Social-ecological challenges in the Yellow River basin (China): A review. Environ. Earth Sci. 2016, 75, 1066. [CrossRef]

33. Li, H.Y.; Man, W.D.; Li, X.Y.; Ren, C.Y.; Wang, Z.M.; Li, L.; Jia, M.M.; Mao, D.H. Remote sensing investigation of anthropogenic land cover expansion in the low-elevation coastal zone of Liaoning Province, China. Ocean Coast. Manag. 2017, 148, 245-259. [CrossRef]

34. Zhao, M.; Derudder, B.; Huang, J. Polycentric development in China's mega-city regions, 2001-2008: A comparison of the Yangtze and Pearl River Deltas. Die Erde-J. Geogr. Soc. Berlin 2017, 148, 1-13.

35. Taubenböck, H.; Wiesner, M. The spatial network of megaregions-Types of connectivity between cities based on settlement patterns derived from EO-data. Comput. Environ. Urban Syst. 2015, 54, 165-180. [CrossRef]

36. Liu, C.; Shi, R. Boundary Data of East Asia Summer Monsoon Geo-Eco-Region (EASMBND). Available online: http://www.geodoi.ac.cn/weben/doi.aspx?Id=165 (accessed on 1 May 2017).

37. Liu, C.; Shi, R. Boundary Data of Asia Tropical Humid \& Semi-Humid Eco-Region (ATHSBND). Available online: http://www.geodoi.ac.cn/weben/doi.aspx?Id=201 (accessed on 1 May 2017).

38. Gorelick, N.; Hancher, M.; Dixon, M.; Ilyushchenko, S.; Thau, D.; Moore, R. Google Earth Engine: Planetary-scale geospatial analysis for everyone. Remote Sens. Environ. 2017, 202, 18-27. [CrossRef]

39. Masek, J.G.; Vermote, E.F.; Saleous, N.E.; Wolfe, R.; Hall, F.G.; Huemmrich, K.F.; Gao, F.; Kutler, J.; Lim, T.K. A Landsat Surface Reflectance Dataset for North America, 1990-2000. IEEE Geosci. Remote Sens. Lett. 2006, 3, 68-72. [CrossRef]

40. USGS. Landsat 8 Surface Reflectance Code (LaSRC) Product Guide: Version 2.0. 2019. Available online: https://www.usgs.gov/media/files/landsat-8-surface-reflectance-code-lasrc-product-guide (accessed on 15 May 2019).

41. Zhu, Z.; Woodcock, C.E. Object-based cloud and cloud shadow detection in Landsat imagery. Remote Sens. Environ. 2012, 118, 83-94. [CrossRef]

42. Pekel, J.F.; Cottam, A.; Gorelick, N.; Belward, A.S. High-resolution mapping of global surface water and its long-term changes. Nature 2016, 540, 418-422. [CrossRef]

43. McFeeters, S.K. The use of the Normalized Difference Water Index (NDWI) in the delineation of open water features. Int. J. Remote Sens. 1996, 17, 1425-1432. [CrossRef]

44. Khorram, S.; Nelson, S.A.C.; Koch, F.H.; van der Wiele, C.F. Remote Sensing; Springer US: Boston, MA, USA, 2012.

45. Cohen, J. A coefficient of agreement for nominal scales. Educ. Psychol. Meas. 1960, 20, 37-46. [CrossRef]

46. Landis, J.R.; Koch, G.G. The measurement of observer agreement for categorical data. Biometrics 1977, 33, 159-174. [CrossRef]

47. Jenks, G.F.; Caspall, F.C. Error on choroplethic maps: Definition, meaurement, reduction. Ann. Assoc. Am. Geogr. 1971, 61, 217-244. [CrossRef]

48. Woodcock, C.E.; Allen, R.; Anderson, M.; Belward, A.; Bindschadler, R.; Cohen, W.; Gao, F.; Goward, S.N.; Helder, D.; Helmer, E.; et al. Free access to Landsat imagery. Science 2008, 320, 1011. [CrossRef]

49. Hamilton, S. Assessing the role of commercial aquaculture in displacing mangrove forest. Bull. Mar. Sci. 2013, 89, 585-601. [CrossRef]

50. Li, X.; Yeh, A.G.O. Analyzing spatial restructuring of land use patterns in a fast-growing region using remote sensing and GIS. Landsc. Urban Plan. 2004, 69, 335-354. [CrossRef]

51. Zhou, Q.; Sun, B. Analysis of spatio-temporal pattern and driving force of land cover change using multi-temporal remote sensing images. Sci. China Technol. Sci. 2010, 53, 111-119. [CrossRef] 
52. WorldBank. East Asia's Changing Urban Landscape: Measuring a Decade of Spatial Growth; World Bank PUBN: Washington, DC, USA, 2015; ISBN 1464803633.

53. Toufique, K.A.; Belton, B. Is aquaculture pro-poor? Empirical evidence of impacts on fish consumption in Bangladesh. World Dev. 2014, 64, 609-620. [CrossRef]

54. Pine, H.J.; Boyd, C.E. Stream salinization by inland brackish-water aquaculture. North Am. J. Aquac. 2011, 73, 107-113. [CrossRef]

55. Xu, C.; Sheng, S.; Zhou, W.; Cui, L.; Liu, M. Characterizing wetland change at landscape scale in Jiangsu Province, China. Environ. Monit. Assess. 2010, 179, 279-292. [CrossRef]

56. Pham, T.D.; Yoshino, K. Impacts of mangrove management systems on mangrove changes in the Northern Coast of Vietnam. Tropics 2016, 24, 141-151. [CrossRef]

57. Richards, D.R.; Friess, D.A. Rates and drivers of mangrove deforestation in Southeast Asia, 2000-2012. Proc. Natl. Acad. Sci. USA 2015, 113, 344-349. [CrossRef]

58. Haas, J.; Ban, Y. Urban growth and environmental impacts in Jing-Jin-Ji, the Yangtze, River Delta and the Pearl River Delta. Int. J. Appl. Earth Obs. Geoinf. 2014, 30, 42-55. [CrossRef]

59. Primavera, J.H. Overcoming the impacts of aquaculture on the coastal zone. Ocean Coast. Manag. 2006, 49, 531-545. [CrossRef]

60. Kuenzer, C.; Ottinger, M.; Liu, G.; Sun, B.; Baumhauer, R.; Dech, S. Earth observation-based coastal zone monitoring of the Yellow River Delta: Dynamics in China's second largest oil producing region over four decades. Appl. Geogr. 2014, 55, 92-107. [CrossRef]

61. Wohlfart, C.; Liu, G.; Huang, C.; Kuenzer, C. A river basin over the course of time: Multi-temporal analyses of land surface dynamics in the Yellow River Basin (China) based on medium resolution remote sensing data. Remote Sens. 2016, 8, 186. [CrossRef]

62. Leichtle, T.; Geiß, C.; Wurm, M.; Lakes, T.; Taubenböck, H. Unsupervised change detection in VHR remote sensing imagery-An object-based clustering approach in a dynamic urban environment. Int. J. Appl. Earth Obs. Geoinf. 2017, 54, 15-27. [CrossRef]

63. Ruddle, K.; Zhong, G. Integrated Agriculture-Aquaculture in South China: The Dike-Pond System of the Zhujiang Delta; Cambridge University Press: Cambridge, UK, 1988; ISBN 9780521341936.

64. Taubenböck, H.; Wiesner, M.; Felbier, A.; Marconcini, M.; Esch, T.; Dech, S. New dimensions of urban landscapes: The spatio-temporal evolution from a polynuclei area to a mega-region based on remote sensing data. Appl. Geogr. 2014, 47, 137-153. [CrossRef]

65. Nghia, N.D.; Lunestad, B.T.; Trung, T.S.; Son, N.T.; Maage, A. Heavy metals in the farming environment and in some selected aquaculture species in the Van Phong bay and Nha Trang bay of the Khanh Hoa province in Vietnam. Bull. Environ. Contam. Toxicol. 2008, 82, 75-79. [CrossRef]

66. Asner, G.P. Cloud cover in Landsat observations of the Brazilian Amazon. Int. J. Remote Sens. 2001, 22, 3855-3862. [CrossRef]

67. Birnie, R.V. Pixel-mixing effects and their significance to identifying snow condition from Landsat MSS data. Int. J. Remote Sens. 1986, 7, 845-853. [CrossRef]

68. Han, J.; Chi, K.; Yeon, Y. Aquaculture feature extraction from satellite image using independent component analysis. In Proceedings of the Machine Learning and Data Mining in Pattern Recognition, Leipzig, Germany, 9-11 July 2005; Perner, P., Imiya, A., Eds.; Springer: Berlin/Heidelberg, Germany, 2005; pp. 660-666.

69. Bush, S.R.; van Zwieten, P.A.M.; Visser, L.; van Dijk, H.; Bosma, R.; de Boer, W.F.; Verdegem, M. Scenarios for Resilient Shrimp Aquaculture in Tropical Coastal Areas. Ecol. Soc. 2010, 15, 15. [CrossRef]

(C) 2019 by the authors. Licensee MDPI, Basel, Switzerland. This article is an open access article distributed under the terms and conditions of the Creative Commons Attribution (CC BY) license (http://creativecommons.org/licenses/by/4.0/). 